\title{
Molecular modelling of urease accessory interaction proteins of Helicobacter Pylori J 99 and predicting an interruption in interaction by Vigna radiata Defensins
}

\author{
Manivannan Paramasivan ${ }^{1}$, Ganesan Sankaran², Naveenkumar Sethuraman ${ }^{2}$, \\ Daniel Selvakumar Devadoss ${ }^{1}$, Sathiamoorthi Thangavelu ${ }^{1}$, Muralitharan \\ Gangatharan $^{1 *}$
}

${ }^{1}$ Department of Microbiology, Bharathidasan University, Tiruchirappalli - 620024, Tamil Nadu, India; ${ }^{2}$ Department of Marine Science, Bharathidasan University,Tiruchirappalli - 620024, Tamil Nadu, India; Muralitharan Gangatharan - Email: gmuralitharan@rediffmail.com; *Corresponding author

\section{Abstract:}

Helicobacter pylori is the major causative agent of Gastric carcinoma. Significance of the urease accessory interaction proteins are emphasized in colonization of human gastric mucosa and efficient infection of $\mathrm{H}$. pylori. Here an attempt is made to explore the structure and properties of urease accessory interaction proteins from Helicobacter pylori J99. The proteins chosen for the study are ureH, ureI, nikR, groL and flgS based on the interaction map available from STRING database. The above mentioned proteins do not have a comprehensive three dimensional structure. Hence the models were generated using PSI-BLAST (Position Specific Iterative-Blast) and MODELLER 9V8. Physicochemical characterization encompasses pI, EC, AI, II and GRAVY. Secondary structure was predicted using PSI-PRED. Functional characterization was done by SOSUI and DISULFIND Servers and refinement of structure was done using Ramachandran plot analysis. RMS-Z values were calculated using Q-MEAN Server and CHIMERA was used for molecular simulation studies. Plant defensins from Vigna radiata are successfully docked to the modeled structures and thus interaction could be possibly prevented. These results will pave way for further selective inhibition of $H$. pylori colonization and in vivo survival by employing plant defensins from Vigna radiata (VrD1 \& VrD2). The work will prove that plant defensins provides anticancer relief too.

Keywords: Helicobacter pylori J99, Urease accessory interaction proteins, Plant defensin, Vigna radiata, Computational tools, Homology model, Docking

\section{Background:}

Helicobacter pylori is a gram negative microaerophilic bacterium causing chronic gastritis, peptic ulcer and gastric carcinoma [1, 2]. The bacterium is able to survive in the hostile environment of the human stomach through the activity of urease. This enzyme catalyses the hydrolysis of urea to ultimately yield ammonium and bicarbonate ions, thus causing an increase of the local acidic $\mathrm{pH}$ of the mucosa for compatible survival of the pathogen [3]. In particular, urease is assembled invivo as an inactive apoenzyme and undergoes a maturation process that involves $\mathrm{Ni}^{2+}$ incorporation and lysine carbamylation to produce a fully active holoenzyme. This assembly requires the significant involvement of urease accessory proteins and thus affirmative from the invivo studies using yeast two hybrid analysis [5, 6], coimmunoprecipation assays [6] which reveals a direct interaction between ureG and ureE. Hence by utilizing the available evidence, the urease accessory proteins and their interacting partners present in STRING database [7] are taken for the present study. In this paper, interacting proteins namely, ureH, ureI, nikR, groL and flgS from Helicobacter pylori J99 which are devoid of a complete structure are chosen for modeling and insilico analysis. Plant defensins are small, basic peptides that have a characteristic three-dimensional folding pattern that is stabilized by eight disulfide-linked cysteines. They are termed plant defensins because they are structurally related to defensins found in other types of organism, including humans [8]. Plant defensins till date act on a wide range of fungi exhibiting antifungal activity which includes plant pathogens. Some plant defensins, however, do not inhibit fungal growth but rather inhibit a-amylase activity and protein synthesis $[\mathbf{9}, \mathbf{1 0}, \mathbf{1 1}, \mathbf{1 2}]$. Alpha-amylase is an insect gut enzyme and it is proposed that inhibition of a-amylase activity results in indigestibility of plant material and thus in defense against feeding insects [13]. Astonishingly, plant defensins that inhibit a-amylase activity however do not exhibit antifungal activity and vice versa [12]. Hence in this study an attempt is also made to dock the $\mathrm{VrD1}$ and VrD2 (Vigna radiata) defensin proteins and urease interaction proteins of Helicobacter pylori J99. Apart from antibacterial colonization activity, the work would sound novel as it also has anticancer activity.

\section{Methodology:}

Sequence retrieval:

Confidence interval map of urease accessory proteins were analyzed from STRING database and availability for authentic structures in Protein data bank was checked comparatively in NCBI Entrez, PDB and SWISSPROT databases. The protein sequences for ureH, ureI, nikR, groL and flgS were retrieved from the STRING database. 
Template generation:

Suitable templates for the above mentioned proteins (1VH4, 2NR1, 2WVF, 1KP8_A and 3D36A) were selected using the homology detection and structure prediction by HMM-HMM comparison in http://toolkit.tuebingen.mpg.de/hhpred/. The templates chosen had an evalue $<1.0$ and similarity $>90 \%$.

\section{Physicochemical characterization:}

Theoretical Isoelectric point (pI), Molecular weight, Number of positive and negatively charged residues, Extinction coefficient, Instability Index, Aliphatic Index and Grand average hydropathicity (GRAVY) were computed using the Expasy's protparam server (http://us.expasy.org/tools/protparam.html).

\section{Secondary structure prediction and functional analysis:}

The SOSUI Server [14] was used to characterize whether the protein is soluble or transmembrane in nature. Disulphide linkages were found by DISULFIND Server [15]. Secondary structure was predicted using PSIPRED Server [16]

\section{Model building and evaluation:}

The modeling of the three dimensional structure of the protein was performed by MODELLER9V8 [17]. The constructed models were energy minimized by CHIMERA [18]. The overall stereochemical properties of the proteins were analyzed in the RAMPAGE Server [19]. The three dimensional structures were further verified by VERIFY3D [20]. RMS-Z score for bond angles of modeled protein structure was estimated by QMEAN Server [21]. The models are viewed in RASMOL.

Analysis of Ligand binding sites and pockets:

Ligand binding site and pockets were predicted by CASTp server [22] and QSITE FINDER [23].

\section{Analysis of protein interaction:}

Protein - protein interaction residues were predicted by PPI-PRED [24].

\section{Docking studies:}

Protein structures of $\mathrm{VrD} 1$ and $\mathrm{VrD} 2$ plant defensins of Vigna radiata was retrieved from Protein Data Bank with Accession numbers 1T15 and 2GL1. Docking between urease interaction proteins and VrD1 and VrD2 proteins was performed by patchdock server [25]. Energy minimization was performed before and after docking using GROMOS96 version of SWISS-PDB Viewer [26].

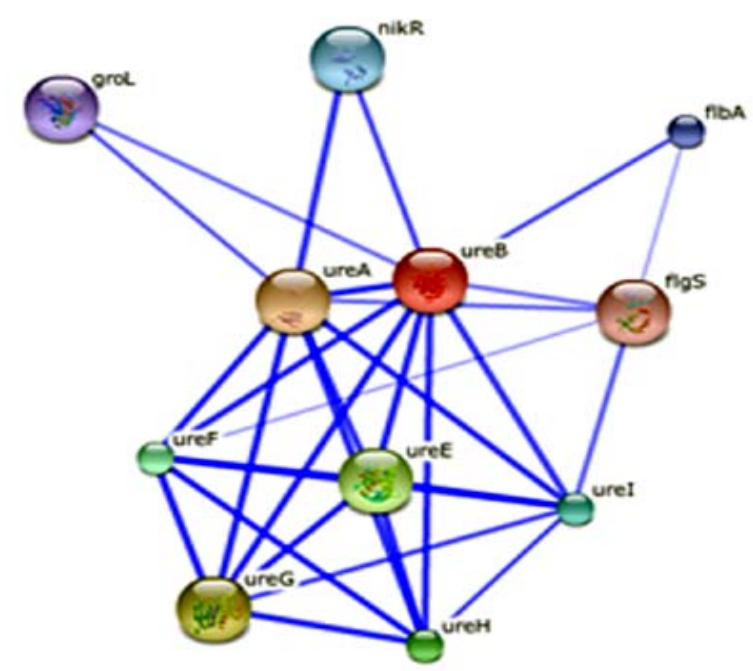

Figure 1: Confidence interval map of urease interaction proteins
Discussion:

The sequences retrieved from STRING database are tabulated in Table 1 (see supplementary material) and physicochemical parameters, SOSUI server results, Disulphide bond patterns and RMS-Z score values are computed and compiled in Table 2, 3, 4 and 5(see Supplementary material) respectively. Confidence interval map of urease interaction proteins are depicted in Figure 1. Figure 2 and Figure 3 illustrates homology modeled structures and their ramachandran plot values indicating the stereochemical properties of the proteins. The urease accessory interaction proteins are inactive in its apo form $[5,6]$ and upon conformational change in to holo enzyme, they require an interaction among nine proteins ranging from ureA to flgS. Among which, four proteins have definitive structure. Hence this paper attempts to model the remaining five structures through homology modeling. Out of the five modeled structures, groL protein was found to be instable. Moreover, the ratio of positively and negatively charged residues was found to be high. It has high molecular weight and functions as heat shock protein homolog. It prevents misfolding and promotes the refolding and proper assembly of unfolded polypeptides generated under stress. Hence, it is affirmative that its structure might be unstable due to the above said function. Instability of groL might also be attributed to the fact that it doesn't contain any tryptophan residues. From Table 3, transmembrane region characteristics are indicative and except for UreI, Rest four proteins modeled are soluble in nature. Disulphide bond patterns are absent in groL and flgS which is indicative that without disulphide bridges also a protein can exist. flgS structure represent the above said phenomenon. No valid RMS-Z score was detected for groL. This also affirms that no valid structure could be generated for the particular protein. Further work is under progress in finding suitable candidates for competitively interacting with urease accessory interaction proteins and thereby inhibiting invivo survival of Helicobacter pylori. Ligand binding sites are indicated in Figure $\mathbf{4}$ and it depicts the interaction by PPI-PRED in Figure 5. Aminoacids in red color represent the interaction sites for protein-protein docking. Docked results affirm the effective interaction between VrD1 and 2 with urease interaction proteins. The docking results show that the Vigna radiata proteins when purified could act as a treatment modality. To be precise, it would efficiently curb the colonization and hinder the colonization efficacy of Helicobacter pylori J99. VrD1 was shown to possess insecticidal activity against bruchids [27] and VrD2 has alpha amylase inhibitory activity [28], however, this report is first of its kind to indicate antibacterial activity together with anticancer possibilities. 


\section{Bioinformation Volume 5}

open access

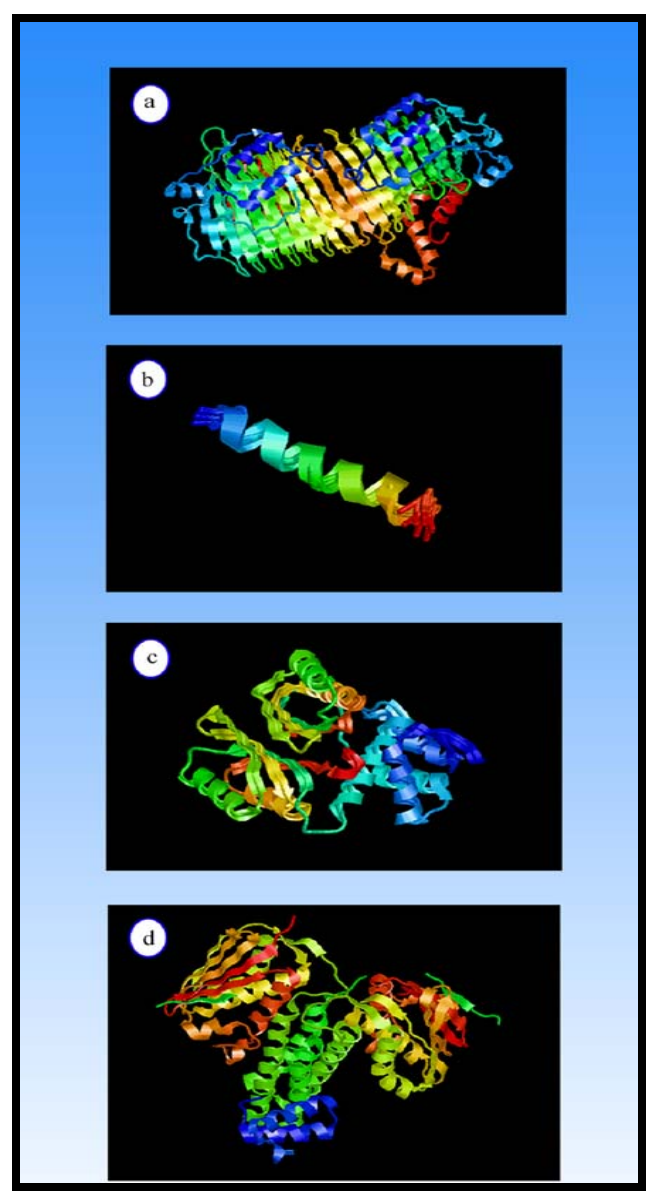

Figure 2: Homology modeled structures
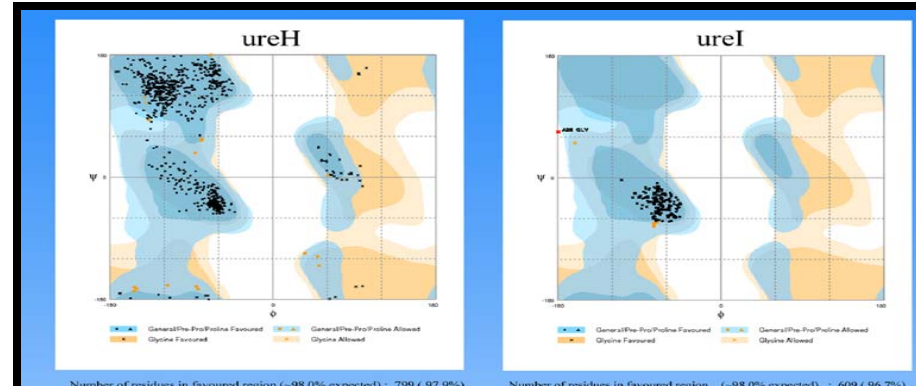

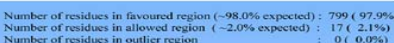

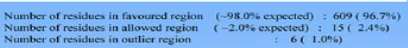

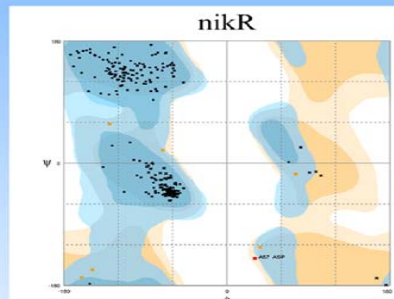

-

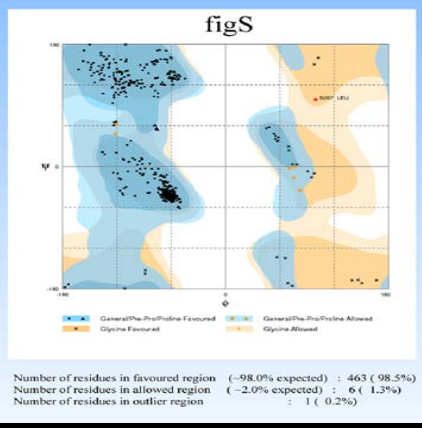

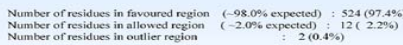

Figure 3: Ramachandran plot analysis of modeled proteins

ISSN 0973-2063 (online) 0973-8894 (print)

Bioinformation 5(10): 410-415 (2011) 


\section{Bioinformation Volume 5}

open access
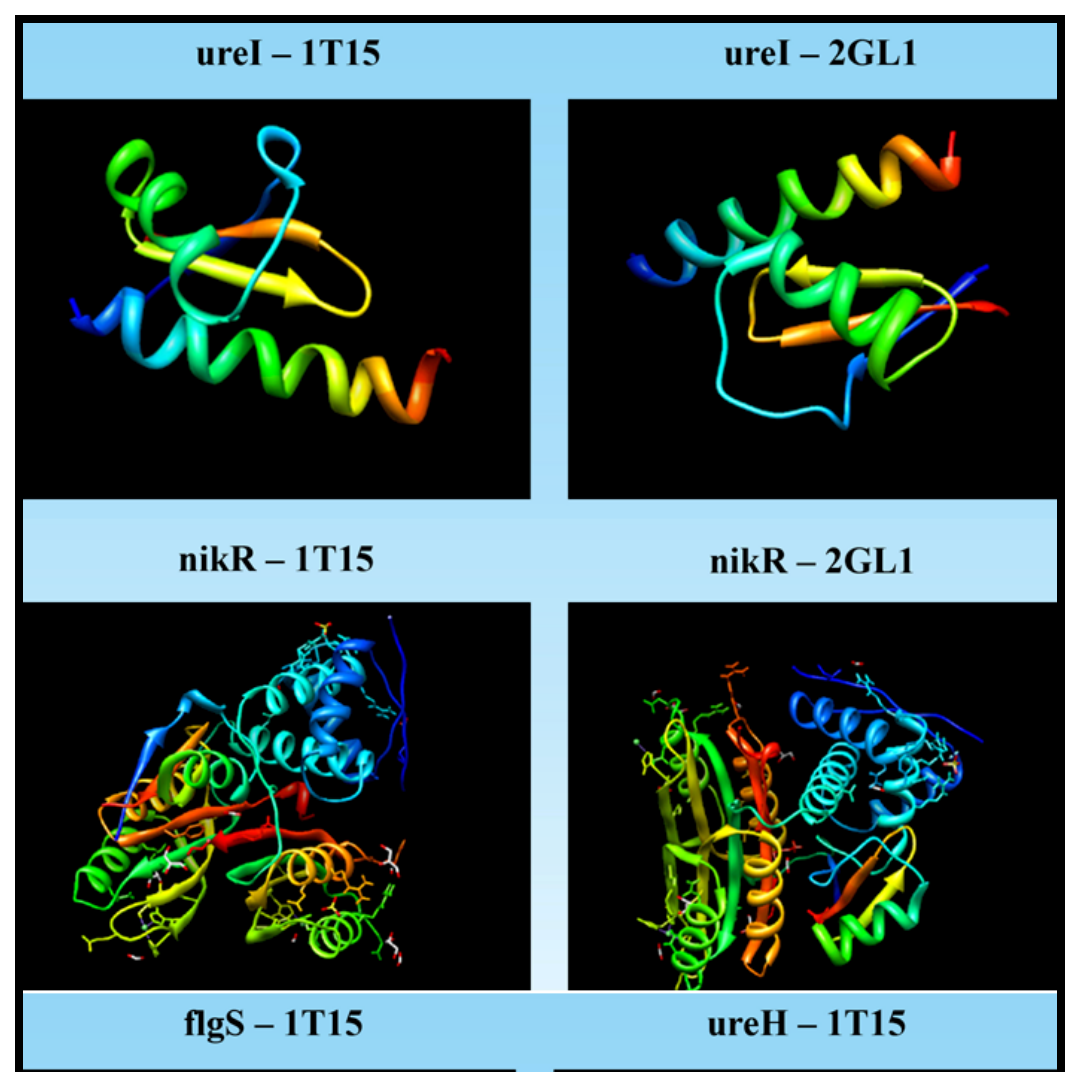

$$
\text { flgS - } 1 \text { T15 }
$$

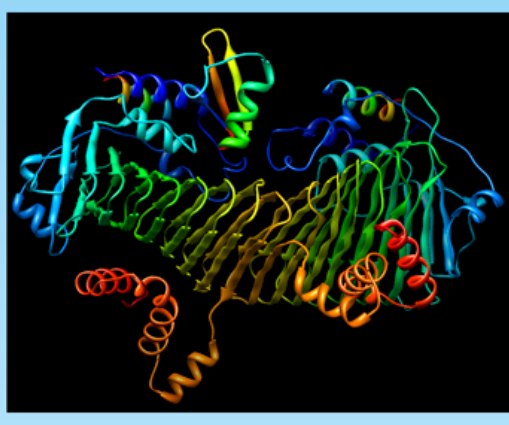

flgS - 2GL1

ureH - 2GL1
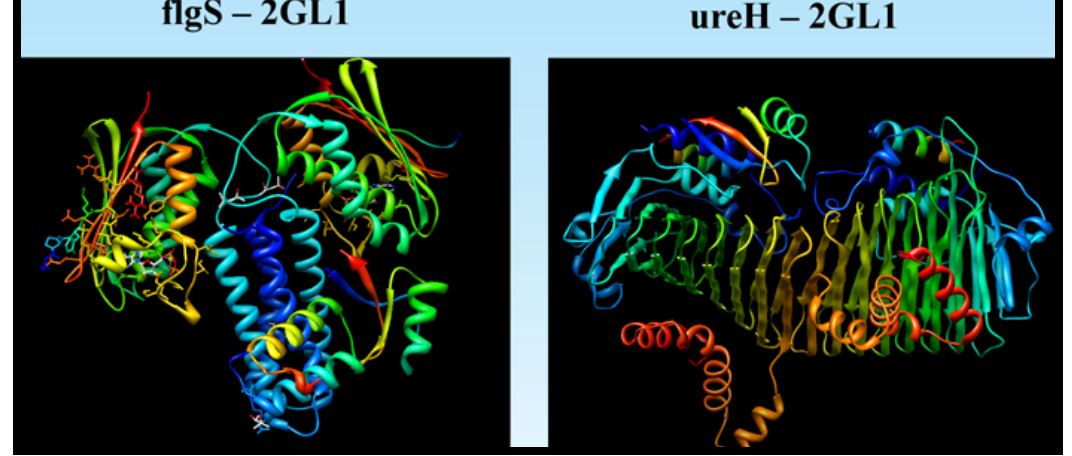

Figure 4: Structure of docked proteins 


\section{Bioinformation}

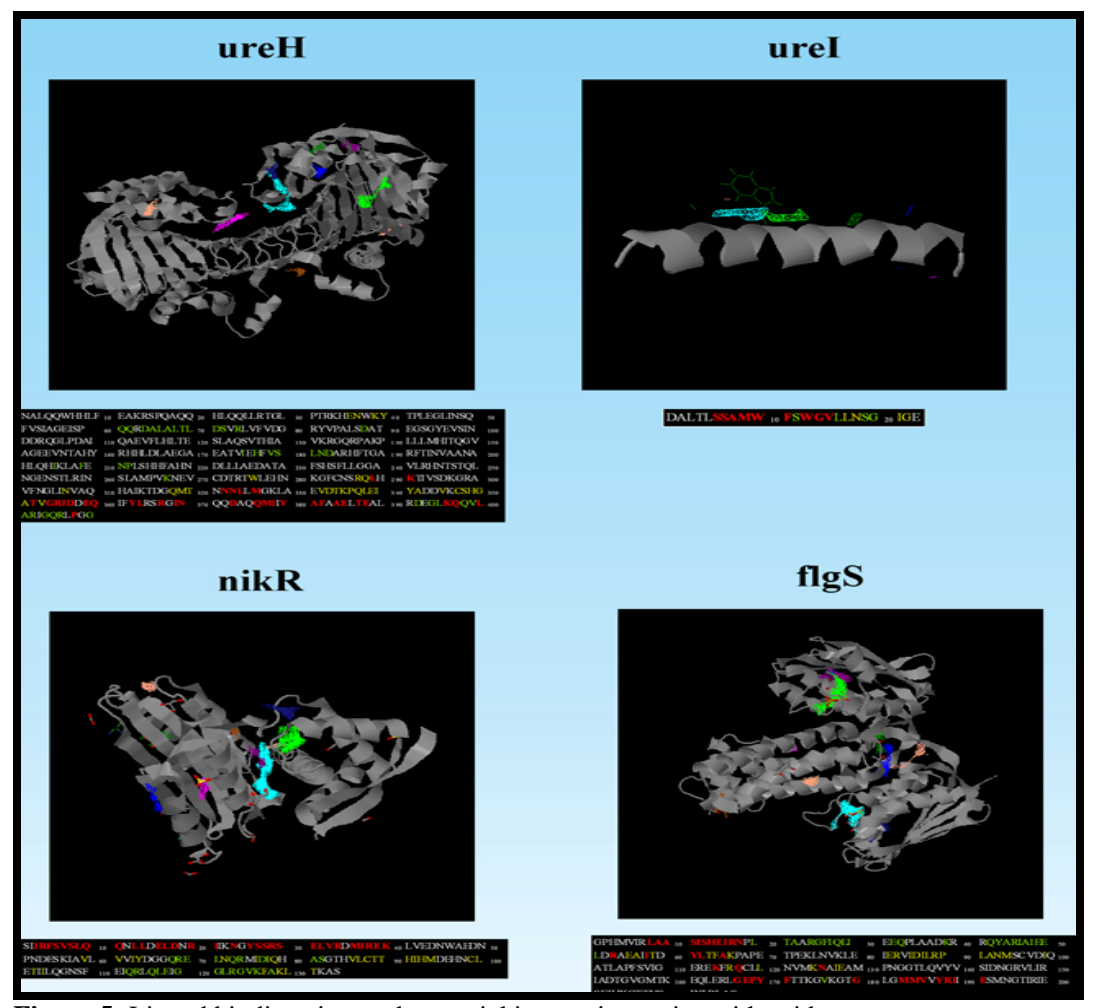

Figure 5: Ligand binding sites and potential interactive aminoacid residues

\section{Conclusion:}

The three dimensional structure models for ureH, ureI, nikR, groL and flgS were generated as described in the methodology. Physicochemical characterization, functional analysis and stereo chemical properties reveal that groL is unstable. The four proteins modeled are efficiently docked to the $\mathrm{VrD} 1$ and $\mathrm{VrD} 2$ plant defensins of Vigna radiata This study is purely a bioinformatics work and pharmacological studies will further pave way for development of specific competitive inhibitors thus hindering colonization and survival of H.pylori in gastric mucosa.

\section{References:}

[1] T Hussell et al. Lancet (1993) 342: 571

[2] AC Wothespoon et al. Lancet (1993) 342: 575

[3] N Dixon et al. J Am chem Soc. (1975) 97: 4131

[4] S Quiroz et al. Nickel and its surprising impact in nature (2007) 2: 519

[5] J Rain et al. Nature (2001) 409: 211 [PMID: 11196647]

[6] P Voland et al. Am J Physiol Gastro intest Liver physiol. (2003) 284: G96

[7] LJ Jenson et al. Nucleic Acids Res. (2009) 37: D412 [PMID: 12519996]

[8] BPHJ Thomma et al. Planta. (2002) 216: 193 [PMID: 12447532]

[9] FJ Colilla et al. FEBS Lett. (1990) 270: 191

[10] E Mendez et al. Eur J Biochem. (1990) 194: 533 [PMID: 2176600]
[11] C Bloch Jr \& M Richardson, FEBS Lett. (1991) 279: 101

[12] RW Osborn et al. FEBS Lett. (1994) 368: 257

[13] RE Shade et al. Bio-Technology (1994) 12: 793

[14] T Hirokawa et al. Bioinformatics (1998) 14(4): 378

[15] A Ceroni et al. Nucleic Acids Res. (2006)34: W177 [PMID: 16844986]

[16] J Dundas et al. Nucleic Acids Res. (2006) 34: W116

[17] AT Laurie \& RM Jackson, Bioinformatics (2005) 21: 1908 [PMID: 15701681]

[18] DT Jones J Mol Biol. (1999) 292: 195 [PMID: 10869041]

[19] Sali \& TL Blundell J Mol Biol. (1993) 234:779 [PMCID: PMC2142932]

[20] EF Pettersen et al. J Comput Chem. (2004) 25(13): 1605 [PMID: 15264254]

[21] SC Lovell et al. Proteins Struct Func \& Genetics. (2002) 50: 437

[22] JU Bowie et al. Science (1991) 253: 164 [PMID: 1853201]

[23] P Benkert et al. Nucleic Acids Res. (2009) 37: W510 [PMID: 19429685]

[24] JR Bradford \& DR Westhead, Bioinformatics (2005) 21: 1487

[25] D Schneidman-Duhovny et al. Nucleic Acids Res (2005) 33: W363

[26] N Guex \& MC Peitsch, Electrophoresis (1997) 18: 2714

[27] YJ Liu et al. Proteins (2006) 63: 777 [PMID: 16544327]

[28] KF Lin et al. Proteins (2007) 68: 530 [PMID: 17444520]

Edited by $P$ Kangueane

Citation: Paramasivan et al. Bioinformation 5(10): 410-415 (2011) License statement: This is an open-access article, which permits unrestricted use, distribution, and reproduction in any medium, for non-commercial purposes, provided the original author and source are credited. 


\section{Supplementary material:}

Table 1: Urease accessory interaction proteins used for the study.

\begin{tabular}{|c|c|c|c|}
\hline $\begin{array}{l}\text { Urease } \\
\text { accessory } \\
\text { interaction } \\
\text { proteins }\end{array}$ & $\begin{array}{l}\text { Accession } \\
\text { number } \\
\text { (from } \\
\text { STRING } \\
\text { database) }\end{array}$ & $\begin{array}{l}\text { Length } \\
\text { (total no. } \\
\text { of amino } \\
\text { acids) }\end{array}$ & Description \\
\hline ureH & Jhp0062 & 265 & $\begin{array}{l}\text { Urease accessory protein ureH; Required for maturation of urease via the functional incorporation of the } \\
\text { urease nickel metallocenter }\end{array}$ \\
\hline ureI & Jhp0066 & 195 & $\begin{array}{l}\text { Urease accessory protein (UreI) (Ure1) (Urease accessory protein ureI); Functions as a specific, } \mathrm{H}(+)- \\
\text { activated urea channel that increases the rate of urea entry into the cytoplasm, resulting in activation of } \\
\text { cytoplasmic urease at acidic medium } \mathrm{pH} \text {. Is essential for H.pylori gastric survival and colonization. Is } \\
\text { necessary for the adaptation of urease activity to the extracellular } \mathrm{pH} \text {, as in the presence of urea, ureI } \\
\text { rapidly enhances the production of ammonia in the extracellular medium when the } \mathrm{pH} \text { of the medium was } \\
\text { decreased to pH5 or below }\end{array}$ \\
\hline nikR & Jhp1257 & 148 & Putative nickel-responsive regulator; Transcriptional regulator (Potential) \\
\hline groL & Jhp0008 & 546 & $\begin{array}{l}\text { HP54K=CHAPERONIN CPN60 heat shock protein homolog; Prevents misfolding and promotes the } \\
\text { refolding and proper assembly of unfolded polypeptides generated under stress conditions (By similarity) }\end{array}$ \\
\hline flgS & Jhp0229 & 381 & putative histidine kinase sensor protein \\
\hline
\end{tabular}

Table 2: Physicochemical parameters of urease accessory interaction proteins.

\begin{tabular}{|c|c|c|c|c|c|c|c|}
\hline $\begin{array}{l}\text { Urease accessory } \\
\text { interaction proteins }\end{array}$ & $\begin{array}{l}\text { Isoelectric } \\
\text { point (pI) }\end{array}$ & $\begin{array}{l}\text { Molecular } \\
\text { Weight (MW) }\end{array}$ & $\begin{array}{l}\text { Negatively } \\
\text { charged } \\
\text { residues (-R) }\end{array}$ & $\begin{array}{l}\text { Positively charged } \\
\text { residues (+ R) }\end{array}$ & $\begin{array}{l}\text { Extinction } \\
\text { coefficient (EC) }\end{array}$ & $\begin{array}{l}\text { Instability } \\
\text { index (II) }\end{array}$ & $\begin{array}{l}\text { Aliphatic } \\
\text { index (AI) }\end{array}$ \\
\hline ureH & 6.39 & 29732.3 & 31 & 29 & 10430 & 47.60 & 92.04 \\
\hline ureI & 5.47 & 21691.5 & 12 & 6 & 72420 & 26.53 & 126.97 \\
\hline nikR & 5.32 & 17069.2 & 24 & 16 & 9970 & 38.57 & 99.39 \\
\hline groL & 5.50 & 58241.0 & 81 & 70 & 13410 & 25.05 & 97.56 \\
\hline flgS & 6.15 & 43650.9 & 53 & 49 & 29910 & 30.04 & 96.27 \\
\hline
\end{tabular}

Table 3: Results of SOSUI Server for urease I (UreI).

\begin{tabular}{lllll}
\hline N terminal & Transmembrane region & C terminal & Type & Length \\
\hline 1 & MLGLVLLYVGIVLISNGICGLTK & 23 & PRIMARY & 23 \\
29 & TAVMNFFVGGLSIVCNVVVITYS & 51 & PRIMARY & 23 \\
74 & SFYGPATGLLFGFTYLYAAINHT & 96 & SECONDARY & 23 \\
106 & WYSLFVAINTVPAAILSHYS & 125 & SECONDARY & 20 \\
142 & WAIIWLAWGVLWLTAFIENILKI & 164 & PRIMARY & 23 \\
171 & PWLAIIEGILTAWIPAWLLFIQ & 192 & PRIMARY & 22 \\
\hline
\end{tabular}

Table 4: Disulphide bond patterns of urease accessory interaction proteins

\begin{tabular}{ll}
\multicolumn{2}{l}{ Table 4: Disulphide bond patterns of urease accessory interaction pro } \\
\hline Urease accessory interaction proteins & No of Disulphide linkages \\
\hline ureH & 5 \\
ureI & 2 \\
nikR & 2 \\
groL & 0 \\
flgS & 0 \\
\hline Urease accessory interaction proteins & RMS-Z score \\
\hline ureH & -0.96 \\
ureI & -0.96 \\
nikR & -0.65 \\
groL & ND* \\
flgS & -1.13 \\
\hline
\end{tabular}

